OPEN ACCESS

Edited by:

Mariangela Caroprese, University of Foggia, Italy

Reviewed by: llias Giannenas,

Aristotle University of

Thessaloniki, Greece

Ioannis S. Pappas,

University of Thessaly, Greece

${ }^{*}$ Correspondence: Mehdi Raissy

mehdi.raissy@iaushk.ac.ir

Specialty section: This article was submitted to Veterinary Infectious Diseases,

a section of the journal

Frontiers in Veterinary Science

Received: 06 November 2021 Accepted: 08 December 2021

Published: 14 January 2022

Citation:

Raissy M, Ahmadi Kabootarkhani M, Sanisales K, Mohammadi M and Rashidian G (2022) The Synergistic Effects of Combined Use of Mentha longifolia, Thymus carmanicus, and Trachyspermum copticum on Growth Performance, Feed Utilization, and Expression of Key Immune Genes in Rainbow Trout (Oncorhynchus mykiss). Front. Vet. Sci. 8:810261 doi: 10.3389/fvets.2021.810261

\section{The Synergistic Effects of Combined Use of Mentha longifolia, Thymus carmanicus, and Trachyspermum copticum on Growth Performance, Feed Utilization, and Expression of Key Immune Genes in Rainbow Trout (Oncorhynchus mykiss)}

\author{
Mehdi Raissy ${ }^{1 *}$, Mehdi Ahmadi Kabootarkhani ${ }^{2}$, Kimia Sanisales $^{2}$, \\ Mohammad Mohammadi ${ }^{2}$ and Ghasem Rashidian ${ }^{3}$ \\ 1 Department of Aquatic Animal Health, Faculty of Veterinary Medicine, Shahrekord Branch, Islamic Azad University, \\ Shahrekord, Iran, ${ }^{2}$ Faculty of Veterinary Medicine, Shahrekord Branch, Islamic Azad University, Shahrekord, Iran, \\ ${ }^{3}$ Department of Aquaculture, Faculty of Natural Resources and Marine Sciences, Tarbiat Modares University, Noor, Iran
}

Medicinal plants exhibit remarkable positive effects on different aspects of fish physiology. This study aimed to evaluate the possible impact of a combination of plants (Mentha Iongifolia, Thymus carmanicus, and Trachyspermum copticum) on growth performance, immune responses and key immune gene expression of rainbow trout. For this purpose, four diets were designed, including zero, $0.25,0.5$, and $1 \%$ of a mixture of plants per $\mathrm{kg}$ of diet, representing dietary treatments of control, T1, T2, and T3, respectively. Two hundred forty fish (weighing $23.11 \pm 0.57 \mathrm{~g}$ ) were fed $3 \%$ of body weight twice a day for 45 days. The results showed that growth parameters of weight gain (except for T1) and FCR were significantly improved in fish receiving all levels of plants, with T3 showing the best growth results. Digestive enzymes activities were notably increased in T1 and T2 compared to the control. Stress biomarkers (glucose and cortisol) were significantly decreased in T1 and T2, while T3 was not significantly different from the control. Immunological responses were significantly improved in T2, while T1 andT3 did not show a statistical difference in terms of lysozyme activity. Catalase activity was noticeably decreased in T1, although superoxide dismutase and malondialdehyde were highest in T2. Immune-related genes were significantly up-regulated in T3 compared to other treatments. Also, antioxidant enzyme coding genes were strongly up-regulated in T2 and T3. Overall, the present results suggest that $1 \%$ inclusion of the mixture of $M$. longifolia, T. carmanicus, and $T$. copticum (T2) can be used to improve the growth and immunity of rainbow trout.

Keywords: medicinal plants, combination of plants, non-specific immunity, immune genes, growth performance, rainbow trout 


\section{INTRODUCTION}

Aquaculture has been exponentially growing during recent decades. However, sustainable development of aquaculture is hindered by several influential factors among which infectious disease has led to economic losses and indiscriminate use of antibiotics (1). In aquaculture, prophylactic measures are extremely important to secure high-quality fish production. The fish innate immunity plays a crucial role in this scenario, and thus the potential of immunostimulants, including medicinal plants (raw material/extracts/essential oils), have been extensively studied aiming to improve growth and immunity of fish (24). The principle of selecting plants for such purposes relies on their traditionally known therapeutics and their main bioactive substances. In addition, plant-based products are less expensive with fewer side effects.

Rainbow trout (Oncorhynchus mykiss) from the Salmonidae family is of economic importance with 916,540 tons of global production in 2019 (5). Several plants have been reported effective on growth performance, digestive enzymes, and immune responses of rainbow trout (6-9). However, few studies have investigated the combined use of plants.

Thymus carmanicus and Mentha longifolia belong to the family Lamiaceae and contain high amounts of polyphenolic compounds contributing to their antioxidative activities (1014). T. carmanicus has been reported to contain large amounts of Linalool, carvacrol, and thymol as major components (15). M. longifolia is wildly spread in vast areas of Europe and Asia with a long history of application in traditional medicine to treat gastrointestinal disorders, cold, fever, spasm, and flatulence (16). The major components present in M. longifolia are pulegone, isomenthone, 1,8-cineole, borneol, and piperitenone oxide (17). A recent study demonstrated $4 \%$ to $6 \%$ inclusion of $M$. longifolia extract was effective on the growth and immunity of Caspian kutum (Rutilus frisii kutum) (18). In addition, Heydari et al. (12) have suggested that $0.2 \%$ and $0.3 \%$ are substantially effective on the immune system of rainbow trout and the expression of TNF$\alpha$ was remarkably increased in fish that received the extract of M. longifolia.

Trachyspermum copticum (Ajowan) belongs to Apiaceae family, with its oval and yellowish fruits as well as its aerial parts (flower and leaves), is used as a diuretic, carminative, and anthelmintic (19). Ajowan has been reported to be a significant antiviral (20), anti-inflammatory (21), antimicrobial (22, 23), and antifungal (24). The main active substances of Ajowan are $P$-Cymene, $\gamma$-Terpinene, Thymol, $\beta$-Pinene, and Myrcene (24).

The current study was designed to assess the possible effects of different dietary levels of combined plants of Thymus carmanicus, Mentha longifoliai, Trachyspermum copticum on digestive enzyme activity, growth performance, biochemical, immune and antioxidant parameters of serum, and expression of immune and antioxidant-related genes in rainbow trout.

\section{MATERIALS AND METHODS}

\section{Collecting Plants}

The seeds of Trachyspermum copticum and leaves of Thymus carmanicus and, Mentha longifolia were procured from a local market. The plants were identified at the Research Center for Medicinal Plants and Ethno-Veterinary, Islamic Azad University, Shahrekord, Iran. All plants were fresh and collected in 2021.

\section{Experimental Diets}

Four different diets were prepared to assess the effects of the plant mixture on rainbow trout's growth performance and immunity. All plant materials were dried, finely powdered, mixed together in equal amounts, and kept in the refrigerator until use. The experimental diets were formulated to contain different levels of zero, $0.5,1$, and $2 \%$ of the mixture of plants per kg diet referred to as control, T1, T2, and T3 respectively. In summary, desired levels of a mixture of powdered plant materials were added to the diet ingredients (Table 1) and vigorously mixed with enough water. Then the paste was cooled at $4^{\circ} \mathrm{C}$ and passed through a grinder. The pelleted feed $(3 \mathrm{~mm})$ was dried at room temperature for $48 \mathrm{~h}$, sieved $(3 \mathrm{~mm})$ and finally coated with $1 \mathrm{ml}$ of fish oil to prohibit leaching. The feed was kept at $4^{\circ} \mathrm{C}$, in clean plastic bags until use.

\section{Feeding and Culture Conditions}

Rainbow trout were secured from a nearby provider and were secured for up to two weeks to adjust to research facility conditions. During this period, the fish were bolstered a basal diet (Kimiagaran. Co, Iran). Afterward, 240 healthy fish (23.11 \pm $0.57 \mathrm{~g}$ ) were distributed in 12 tanks and fed $3 \%$ of their respective biomass twice daily for 45 days. During the experiment, tanks were aerated using air stones and uneaten feed was removed from the tanks. Physiochemical parameters of rearing water including temperature, $\mathrm{pH}$, Dissolved Oxygen and hardness $\left(\mathrm{CaCO}_{3}\right)$ were

TABLE 1 | Diet formulation of experimental diets incorporated with different levels of zero (Control), $0.5 \%$ (T1), 1\% (T2), and 2\% (T3) of a mixture of herbs (Thymus carmanicus, Mentha longifolia, Trachyspermum copticum).

\begin{tabular}{lcccl}
\hline T3 & T2 & T1 & Control & Ingredients (\%) \\
\hline 34 & 34 & 34 & 34 & Fish meal \\
2 & 1 & 0.5 & 0 & TMT $^{1}$ \\
17.5 & 17.5 & 17.5 & 17.5 & Corn gluten \\
18.0 & 18.0 & 18.0 & 18.0 & Wheat flour \\
4.8 & 4.8 & 4.8 & 4.8 & Sunflower oil \\
14.0 & 14.0 & 14.0 & 14.0 & Soybean meal \\
3.6 & 3.6 & 3.6 & 3.6 & Rice bran \\
2.3 & 2.3 & 2.3 & 2.3 & Fish oil \\
1.5 & 1.5 & 1.5 & 1.5 & Vitamin premix \\
1.5 & 1.5 & 1.5 & 1.5 & Mineral premix \\
2.0 & 2.0 & 2.0 & 2.0 & Molasses \\
0.03 & 0.03 & 0.03 & 0.03 & L-Carnitine \\
0.70 & 0.70 & 0.70 & 0.70 & Salt \\
0.02 & 0.02 & 0.02 & 0.02 & Vitamin C \\
\hline
\end{tabular}

${ }^{1}$ Thymus carmanicus, Mentha longifolia, Trachyspermum copticum; ${ }^{2}$ Vitamin premix: retinol acetate (A), $6000 \mathrm{IU}$; Cholecalciferol (D3), $2250 \mathrm{UU}$; DL-atocopheryl acetate (E), 225 mg; menadione sodium bisulfite (K3), 15 mg; L-ascorbic acid (C), 700 mg; Dbiotin(H2), O/6 mg; thiamin mononitrate (B1), $36 \mathrm{mg}$; riboflavin (B2), $45 \mathrm{mg}$; calcium D-pantothenate (B3), $7200 \mathrm{mg}$; niacin amide (B5), $135 \mathrm{mg}$; pyridoxine hydrochloride (B6), $36 \mathrm{mg}$; folic acid (B9), $9 \mathrm{mg}$; cyanocobalamin (B12), 0/045 mg; antioxidant $75 \mathrm{mg},{ }^{3}$ Mineral premix: mineral: $\mathrm{Fe}, 45 \mathrm{mg}$; Cu, 5/4 mg; Co, 0.75mg; Se, 0.15 mg; Zn, $75 \mathrm{mg}$; Mn 5/37 mg; I, 5/4 mg; cholinechloride, $2250 \mathrm{mg}$. 
measured as $17 \pm 1^{\circ} \mathrm{C}, 7.52 \pm 0.22,7.2 \pm 0.39 \mathrm{mg} \cdot \mathrm{ml}^{-1}$ and 164.9 \pm 18 during the experiment. The photoperiod was set as $12 \mathrm{~L}: 12 \mathrm{D}$ using artificial light.

\section{Sampling}

The sampling procedures were in accordance with our previous publication (25) with slight modifications. Blood samples were drained from six randomly selected fish per replicate after $24 \mathrm{~h}$ starvation. Fish were anesthetized with clove powder (50 mg. $\mathrm{ml}^{-1}$ ), blood was drained from the caudal vein using $2 \mathrm{ml}$ heparinized syringes, then samples were left to clot at room temperature, centrifuged at 3,000 rpm for $10 \mathrm{~min}$, and kept at $-20^{\circ} \mathrm{C}$ until further investigation. Three fish were randomly selected for collecting skin mucus, placed in small plastic bags holding $5 \mathrm{ml}$ of saline buffer $(0.09 \% \mathrm{NaCl})$ for $1 \mathrm{~min}$ while gently rubbing fish from the operculum toward the tail. Three fish were euthanized using an overdose of clove powder $\left(200 \mathrm{mg} \cdot \mathrm{ml}^{-1}\right)$ and dissected in an aseptic condition. The liver and intestine were snap-frozen in liquid nitrogen for gene expression studies. Three fish were also euthanized in the same manner, and the whole digestive tract was extracted to measure digestive enzymes' activity. The complete digestive tract was thoroughly washed with distilled water then homogenized using an electric homogenizer (IKA T25 digital, Ultra Turrax model) on ice flakes in 10 volumes (w/v) of cold physiological serum. Subsequently, samples were centrifuged at $6,000 \mathrm{~g}$ for $20 \mathrm{~min}$ at $4^{\circ} \mathrm{C}$. The supernatants were then stored at $-80^{\circ} \mathrm{C}$ in new tubes until further evaluation.

\section{Growth Parameters}

At the end of the experiment, growth parameters of final weight (precision of $0.01 \mathrm{~g}$ ), weight gain (WG), specific growth rate (SGR), feed conversion ratio (FCR), and survival rate (SR), were measured based on the following equations:

$$
\begin{aligned}
\text { WG }(\mathrm{g}) & =\text { Final weight }- \text { Initial weight } \\
\mathrm{FCR} & =\text { Total Feed Given }(\mathrm{g}) / \text { Weight gain }(\mathrm{g}) \\
\mathrm{SGR}\left(\% . \mathrm{d}^{-1}\right) & =(\{\text { Ln final wt }(\mathrm{g})-\text { Ln initial wt }(\mathrm{g})\} / \text { days }) \\
& \times 100 ; \\
\mathrm{SR}(\%) & =(\text { final numbers/initial numbers }) \times 100 .
\end{aligned}
$$

\section{Digestive Enzymes Activity}

Protease was evaluated using the casein hydrolysis method (26). The absorbance of the supernatant was valued at $280 \mathrm{~nm}$ beside L-tyrosine that was used as standard. The amount of enzyme that secreted one mmol of tyrosine $\mathrm{ml}^{-1} \mathrm{~min}^{-1}$ was determined to be one unit of protease activity. The method described by Bernfeld (27) was applied to measure amylase activity. Maltose was used as the standard substance, and absorbance was read at $600 \mathrm{~nm}$. The amount of enzyme that produced one $\mathrm{mmol}$ maltose $\mathrm{ml}^{-1} \cdot \mathrm{min}^{-1}$ was determined as one unit of amylase activity. Lipase activity was evaluated based on the assessment of enzyme hydrolysis, diacylglycerols, triacylglycerols and monoacylglycerols to free fatty acids in olive oil emulsion. The hydrolysis of 1.0 micro equivalent of fatty acids from triacylglycerol in $1 \mathrm{~h}$ with a $\mathrm{pH}$ of 7.7 and temperature of $37^{\circ} \mathrm{C}$ was selected as one unit of lipase activity.

\section{Assessment of Serum Biochemical Parameters}

Serum total protein, albumin, triglyceride, glucose, cortisol and cholesterol were measured by Pars Azmun kits (Pars Azmun, Iran) in line with the kit's instructions. The activity of alkaline phosphatase (ALP), aspartate transaminase (AST) and alkaline transaminase (ALT) were evaluated calorimetrically at the wavelength $540 \mathrm{~nm}$ using ready-made kits (Pars Azmun, Iran) under the kit's guidelines.

\section{Serum Innate Immune Responses}

The recommended protocol by Ghafarifarsani et al. (28) was followed to measure lysozyme activity. In summary, $175 \mu$ l of Micrococcus luteus (Sigma, M 3770, St. Louis, USA) suspension $\left(75 \mu \mathrm{g} . \mathrm{ml}^{-1}\right)$ was prepared in $0.1 \mathrm{M}$ phosphate citrate buffer (pH 5.8) mixing it with $25 \mu \mathrm{l}$ of fish homogenate samples. A microplate reader (Hiperion, Germany) was used to record the changes in turbidity at $450 \mathrm{~nm}$ for a continuous $5 \mathrm{~min}$. The quantity of lysozyme leading to absorbance reduction with rates of $0.001 / \mathrm{min}$ was considered one unit of lysozyme activity for each $\mathrm{mg}$ of sample.

Alternative complement activity was assessed according to the sheep red blood cell hemolysis (SRBC), following the procedure described by Ortuño et al. (29). The sample volume, which consisted of 50\% hemolysis, was set and was utilized to evaluate the complement activity of the samples (value of ACH50 are in units.ml ${ }^{-1}$ ). A lysis curve was formed on checkered paper to evaluate the quantity of intermediate activity on the complement (Log-Log Graph). Complement activity is calculated using the following equation and based on the amount of serum that caused $50 \%$ hemolysis.

$$
\operatorname{ACH} 50(\mathrm{U} / \mathrm{ml})=\mathrm{k} \times 0.5 \times(\text { dilution factor }) .
$$

$\mathrm{K}$ is the amount of serum in $\mathrm{ml}$ that yielded $50 \%$ hemolysis, 0.5 is constant, and the dilution factor in this experiment was considered 0.01 since the serum was diluted 100 times.

Serum total Ig was measured according to the method presented by Siwicki et al. (30). Protease activity was assessed by the azocasein hydrolysis method as described by Ross et al. (31). Total protein content in samples was assayed by commercial kits (Pars Azmun, Iran) in line with the given instructions. The activity of acid phosphatase was measured using a commercially available kit (Darman Faraz Kaveh, Iran) following manufacturer's instructions.

\section{Antioxidant Parameters}

The serum concentration of superoxide dismutase (SOD), catalase (CAT), glutathione reductase (GR), and malondialdehyde (MDA) were measured by ZelBio kits (Zelbio, Germany) in accordance with the kits' instructions.

\section{Gene Expression Study}

RNA extraction was carried out on intestine and liver samples by RNX-Plus (Sinaclon, Tehran, Iran) according to the manufacturer's instructions. Then cDNA was constructed using $1.00 \mu \mathrm{g}$ of RNA (Sinaclon, Tehran, Iran) which was preserved at $-20^{\circ} \mathrm{C}$ until further tests. 
A 2X SYBR green master mix (Sinaclon, Tehran, Iran) was used to amplify the constructed cDNA in real time PCR (StepOne, Applied Biosystem). In brief, $1 \mu \mathrm{l}$ cDNA and $0.2 \mu \mathrm{l}$ primers were added to $5 \mu \mathrm{l}$ of $2 \mathrm{X}$ SYBR green PCR Master Mix and the volume was raised to $10 \mu \mathrm{l}$ using DEPC-treated water. The real-time PCR conditions are provided in supplementary materials. The primers were designed using Primer3 software based on existing cDNA sequences in the GenBank. The threshold cycle (CT) was determined and normalized to GAPDH as reference gene. The relative expression of selected genes was determined according to Livak and Schmittgen (32) and iQ5 optical system software version 2.0 (Bio- Rad, USA) was used to analyze data.

\section{Statistical Analysis}

The study outline was planned and carried out in an absolute randomized design. After which, statistical analysis of data was conducted. Later inspection of the normality of their distribution by the Kolmogorov-Smirnov test, using one-way analysis of variance (one-way ANOVA) as well as Tukey's HSD post-hoc test in SPSS software version 20 was conducted and statistical significance was considered $p<0.05$.

\section{RESULTS}

\section{Growth Performance}

Rainbow trout growth parameters fed with experimental diets for 45 days are presented in Table 2. Results showed that the individuals from $\mathrm{T} 2$ and $\mathrm{T} 3$ had a significantly better performance when compared to the control fish $(p<0.05)$. According to the results, the lowest feed conversion ratio and the highest SGR were found in T3. No mortality was observed during the experiment in all treatments. No significant difference was found in WG and SGR values between the control and T1 groups $(p>0.05)$.

\section{Digestive Enzyme Activity}

At the end of the dietary experiment, the activity of digestive enzymes, including protease, amylase, and lipase, were measured as presented in Table 3. The highest activity of amylase was

TABLE 2 | Growth performance of rainbow trout fed diets incorporated with different levels of zero (Control), 0.5\% (T1), 1\% (T2) and 2\% (T3) of a mixture of herbs (Mentha longifolia, Thymus carmanicus, Trachyspermum copticum) for 45 days.

\begin{tabular}{lcccr}
\hline Parameters & Control & T1 & \multicolumn{1}{c}{ T2 } & \multicolumn{1}{c}{ T3 } \\
\hline Initial weight (g) & $22.85 \pm 0.99$ & $24.22 \pm 1.67$ & $22.59 \pm 1.28$ & $22.79 \pm 1.34$ \\
Final weight (g) & $40.82 \pm 1 / 52$ & $42.94 \pm 1 / 74$ & $42.12 \pm 2 / 08$ & $42.57 \pm 1.27$ \\
Weight gain (g) & $17.98 \pm 0 / 92^{\mathrm{b}}$ & $18.72 \pm 1 / 02^{\mathrm{ab}}$ & $19.53 \pm 0 / 28^{\mathrm{a}}$ & $19.78 \pm 0.28^{\mathrm{a}}$ \\
SGR $\left(\% \mathrm{~d}^{-1}\right)$ & $1.29 \pm 0.02^{\mathrm{b}}$ & $1.27 \pm 0.01^{\mathrm{b}}$ & $1.38 \pm 0.00^{\mathrm{a}}$ & $1.39 \pm 0.01^{\mathrm{a}}$ \\
FCR & $1.40 \pm 0.07^{\mathrm{a}}$ & $1.21 \pm 0.06^{\mathrm{b}}$ & $1.17 \pm 0.01^{\mathrm{b}}$ & $1.14 \pm 0.02^{\mathrm{b}}$ \\
Survival rate & $100.00 \pm 0.00^{\mathrm{a}}$ & $100.00 \pm 0.00^{\mathrm{a}}$ & $100.00 \pm 0.00^{\mathrm{a}}$ & $100.00 \pm 0.00^{\mathrm{a}}$ \\
(\%) & & & & \\
\hline
\end{tabular}

SGR, specific growth rate; FCR, feed conversion ratio. Data represent mean $\pm S E$. Different letters in the same row indicate significant differences $(p<0.05)$. found in T1 followed by T2, both significantly different from the control fish $(p<0.05)$. The measured values from T3 were statistically different from the control $(p<0.05)$. However, a reduction in enzyme activity was observed in comparison to the other treatments with a lower inclusion level. Similar results were observed for lipase, with a gradual reduction in enzyme activity as the inclusion level increased. For protease activity, both T1 and $\mathrm{T} 2$ were found significantly higher when compared to the control and T3 group. This finding, however, was similar to the results from amylase activity. No statistical difference was found between $\mathrm{T} 1$ and $\mathrm{T} 2$.

\section{Serum Biochemistry}

Biochemical parameters measured in fish serum after 45 days of the dietary experiment are presented in Table 4. The highest serum total protein level was present in $\mathrm{T} 2$ followed by $\mathrm{T} 1$, and all treatments were significantly different from the control. Similar results were also found for albumin. The lowest values were observed in T1 in terms of cholesterol and triglyceride, with no significant difference from the control. Triglyceride in T2 was also statistically different from that of the control. Based on the

TABLE 3 | Digestive enzymes of serum of rainbow trout fed diets incorporated with different levels of zero (Control), $0.5 \%$ (T1), 1\%(T2) and 2\% (T3) of a mixture of herbs (Mentha longifolia, Thymus carmanicus, Trachyspermum copticum) for 45 days.

\begin{tabular}{lcccc}
\hline Parameters & Control & T1 & T2 & T3 \\
\hline $\begin{array}{l}\text { Amylase } \\
(\mathrm{U} / \mathrm{mg} \mathrm{prot})\end{array}$ & $23.38 \pm 0.54^{\mathrm{c}}$ & $40.56 \pm 0.29^{\mathrm{a}}$ & $40.63 \pm 0.49^{\mathrm{a}}$ & $32.54 \pm 0.10^{\mathrm{b}}$ \\
$\begin{array}{l}\text { Lipase }(\mathrm{U} / \mathrm{mg} \\
\text { prot })\end{array}$ & $1.99 \pm 0.05^{\mathrm{d}}$ & $3.68 \pm 0.08^{\mathrm{a}}$ & $3.10 \pm 0.09^{\mathrm{b}}$ & $2.30 \pm 0.04^{\mathrm{c}}$ \\
$\begin{array}{l}\text { Protease }(\mathrm{U} / \\
\text { mg prot) }\end{array}$ & $6.23 \pm 0.07^{\mathrm{c}}$ & $10.19 \pm 0.04^{\mathrm{a}}$ & $10.36 \pm 0.15^{\mathrm{a}}$ & $8.18 \pm 0.04^{\mathrm{b}}$ \\
& & & &
\end{tabular}

Data represent mean $\pm S E$. Means with different letters $(a-d)$ in the same row indicate significant differences $(P<0.05)$.

TABLE 4 | Biochemical parameters of rainbow trout fed diets incorporated with different levels of zero (Control), 0.5\% (T1), 1\% (T2) and 2\% (T3) of a mixture of herbs (Mentha Iongifolia, Thymus carmanicus, Trachyspermum copticum) for 45 days.

\begin{tabular}{|c|c|c|c|c|}
\hline Parameters & Control & T1 & T2 & T3 \\
\hline $\begin{array}{l}\text { Total protein } \\
\text { (g/L) }\end{array}$ & $1.43 \pm 0 / 00^{c}$ & $1.77 \pm 0.02^{\mathrm{ab}}$ & $1.85 \pm 0 / 03^{a}$ & $1.63 \pm 0 / 08^{b}$ \\
\hline Albumin (g/L) & $0.62 \pm 0.01^{c}$ & $0.85 \pm 0.02^{a}$ & $0.86 \pm 0.01^{a}$ & $0.73 \pm 0 / 03^{b}$ \\
\hline $\begin{array}{l}\text { Triglyceride } \\
\text { (mg/dL) }\end{array}$ & $108.00 \pm 5.13^{a}$ & $65.00 \pm 1.15^{c}$ & $94.00 \pm 2.08^{b}$ & $115.00 \pm 4.04^{a}$ \\
\hline $\begin{array}{l}\text { Cholesterol } \\
\text { (mg/dL) }\end{array}$ & $85.33 \pm 4.33^{a}$ & $58.66 \pm 4.70^{b}$ & $79.33 \pm 0.88^{a}$ & $86.00 \pm 1.52^{a}$ \\
\hline $\begin{array}{l}\text { Glucose } \\
\text { (mg/dL) }\end{array}$ & $65.66 \pm 1.20^{a}$ & $44.33 \pm 1.85^{c}$ & $54.00 \pm 2.08^{b}$ & $65.33 \pm 1.20^{a}$ \\
\hline $\begin{array}{l}\text { Cortisol } \\
(\mathrm{nmol} / \mathrm{L})\end{array}$ & $17.60 \pm 0 / 43^{a}$ & $16.10 \pm 0.35^{b}$ & $15.00 \pm 0.25^{c}$ & $16.63 \pm 0.08^{a b}$ \\
\hline
\end{tabular}

Data represent mean $\pm S E$. Different letters $(a-c)$ in the same row indicate significant differences $(p<0.05)$. 
results, stress biomarkers (glucose and cortisol) were strongly reduced in T1 and T2 compared to the control and T3 groups with no significant difference.

\section{Immune Responses}

Serum immunological parameters, including lysozyme, alternative complement hemolytic activity (ACH50), total immunoglobulin (total Ig), and acid phosphatase (ACP) activity, were measured (Table 5). Lysozyme activity had increased in all experimental diets compared to the control; however, only T2 was statistically different $(p<0.05)$. Results showed that ACH50 was the highest in T2, quite different from all other treatments. However, with no significant difference, ACH50 in T1 and T3 was higher than the control and lower than T2. Total Ig was found to be augmented in T1, and T2 followed by T3, all of which were meaningfully different from the control group ( $p$ $<0.05)$. The activity of ACP was remarkably decreased in T1 followed by T3 and T2, while the highest ACP activity was found in the control group.

\section{Antioxidant Parameters}

The antioxidant parameters, including CAT, SOD, MDA, and GR were determined in serum samples, and results are shown in Table 6. According to the results, the highest level of CAT was in the control group, while SOD was highest in T2. The values for MDA were found to be higher in experimental treatments in comparison to the control $(p<0.05)$, with T2 showing the highest MDA content.

\section{Skin Mucus Immunological Parameters}

The results from measured immune responses of protease, ALP, total immunoglobulin, lysozyme, and $\mathrm{ACH} 50$ are depicted in Figure 1. Protease was effectively influenced in T2. However, T1 and T3 were also found significantly higher than control $(p<$ 0.05 ). For ALP, T2 showed the lowest value, followed by T3. Total Ig was increased in T1 but not different from control, while T2 and T3 showed a significantly higher value than T1 and control. Similar results were found for lysozyme, except that T3 led to the highest values. In terms of ACH50, individuals from T3 treatment had higher values compared to other treatments. There

TABLE 5 | Serum immunological parameters of rainbow trout fed diets incorporated with different levels of zero (Control), 0.5\% (T1), 1\% (T2) and 2\% (T3) of a mixture of herbs (Mentha longifolia, Thymus carmanicus, Trachyspermum copticum) for 45 days.

\begin{tabular}{lcccc}
\hline Parameters & Control & T1 & T2 & T3 \\
\hline $\begin{array}{l}\text { Lysozyme } \\
(\mathrm{U} / \mathrm{ml})\end{array}$ & $32.66 \pm 0.88^{\mathrm{b}}$ & $34.00 \pm 0.57^{\mathrm{b}}$ & $40.00 \pm 1.52^{\mathrm{a}}$ & $35.66 \pm 0.33^{\mathrm{b}}$ \\
$\mathrm{ACH} \mathrm{H}_{50}$ & $135.33 \pm 0.33^{\mathrm{c}}$ & $139.00 \pm 0.57^{\mathrm{b}}$ & $145.33 \pm 1.45^{\mathrm{a}}$ & $138.33 \pm 0.33^{\mathrm{b}}$ \\
$(\mathrm{U} / \mathrm{ml})$ & & & & \\
$\begin{array}{l}\text { Total lg } \\
(\mathrm{mg} / \mathrm{ml})\end{array}$ & $8.71 \pm 0.03^{\mathrm{c}}$ & $10.90 \pm 0.14^{\mathrm{a}}$ & $11.29 \pm 0.18^{\mathrm{a}}$ & $10.18 \pm 0.0 .16^{\mathrm{b}}$ \\
$\mathrm{ACP}(\mathrm{U} / \mathrm{ml})$ & $1.53 \pm 0.03^{\mathrm{a}}$ & $0.87 \pm 0.00^{\mathrm{d}}$ & $0.95 \pm 0.00^{\mathrm{c}}$ & $1.04 \pm 0.02^{\mathrm{b}}$ \\
\hline
\end{tabular}

Ig, immunoglobulin; ACP, acid phosphatase. Data represent mean \pm SE. Different letters in the same row indicate significant differences $(p<0.05)$. was no significant difference between $\mathrm{T} 1$ and $\mathrm{T} 2$, while both were significantly higher than control $(p<0.05)$.

\section{Gene Expression}

The relative expression of immune and antioxidant genes are represented in Figures 2, 3. Immune-related genes including $I L$ $1 \beta, I L-8$, and $L y s$ were significantly up-regulated in T3, while no statistical difference was found when comparing T1 and T2 with the control group $(p>0.05)$. The results also showed that antioxidant genes coding GPx, SOD, and CAT were highly expressed in T3 and T2 compared to T1 and control groups.

\section{DISCUSSION}

According to the present results, a synergistic effect of $T$. carmanicus, M. longifolia, and T. copticum (TMT) was identified on rainbow trout growth (weight gain and FCR) and immune response (lysozyme and ACH50 activity). These parameters were found to be highly improved in T2 group. In addition, immune and antioxidant-related genes were modulated by the inclusion of a combination of plants. A notable upregulation was observed for pro-inflammatory genes $(I L-1 \beta$ and $I L-8)$, as well as $T N F-\alpha$.

The beneficial effects of inclusion of medicinal plants in aquafeeds have been previously reported $(2,3)$. Although, the exact mechanism of action of medicinal plants on fish growth or immune system is not yet fully understood. It is suggested that these positive effects on animals are due to different bioactive compounds found in medicinal plants including flavonoids, phenolics, alkaloids, saponins, terpenoids, tannins, glycosides, steroids or essential oils $(3,33)$.

In this study, three plants containing several substances such as carvacrol and thymol have been previously found effective on fish $(34,35)$. Previous reports testing different levels of carvacrol and thymol suggested their positive effects on growth performance and immunity of rainbow trout $(36,37)$. Present findings showed better results for growth parameters of WG and FCR in higher inclusion levels of plants (T2 and T3). It suggests a synergistic effect at higher inclusion levels that can be attributed to the major components of the plants. It has been reported that the addition of plant extracts into the fish diet can stimulate appetite (38-40) and increase food intake, which in turn improves growth performance (41). Other researchers have

TABLE 6 | Serum antioxidant indices and MDA content of rainbow trout fed diets incorporated with different levels of zero (Control), 0.5\% (T1), 1\% (T2) and 2\% (T3) of a mixture of herbs (Mentha longifolia, Thymus carmanicus, Trachyspermum copticum) for 45 days.

\begin{tabular}{lcccc}
\hline Parameters & Control & T1 & T2 & T3 \\
\hline CAT $(\mathrm{U} / \mathrm{ml})$ & $70.93 \pm 0.26^{\mathrm{a}}$ & $64.16 \pm 0.96^{\mathrm{c}}$ & $67.46 \pm 0.52^{\mathrm{b}}$ & $69.06 \pm 0.86^{\mathrm{ab}}$ \\
$\mathrm{SOD}(\mathrm{U} / \mathrm{ml})$ & $90.30 \pm 0.50^{\mathrm{d}}$ & $92.70 \pm 0.49^{\mathrm{c}}$ & $97.43 \pm 0.52^{\mathrm{a}}$ & $95.43 \pm 0.66^{\mathrm{b}}$ \\
$\mathrm{MDA}$ & $63.83 \pm 0.92^{\mathrm{c}}$ & $76.10 \pm 0.87^{\mathrm{a}}$ & $77.53 \pm 1.21^{\mathrm{a}}$ & $72.16 \pm 1.29^{\mathrm{b}}$ \\
$(\mathrm{mmol} / \mathrm{ml})$ & & & & \\
GR $(\mathrm{U} / \mathrm{ml})$ & $1063.33 \pm 26.66^{\mathrm{c}}$ & $1277.66 \pm 7.31^{\mathrm{a}}$ & $1250.00 \pm 7.63^{\mathrm{a}}$ & $1156.66 \pm 10.72^{\mathrm{b}}$
\end{tabular}

Data represent mean $\pm S E$. Different letters in the same row indicate significant differences $(p<0.05)$. 


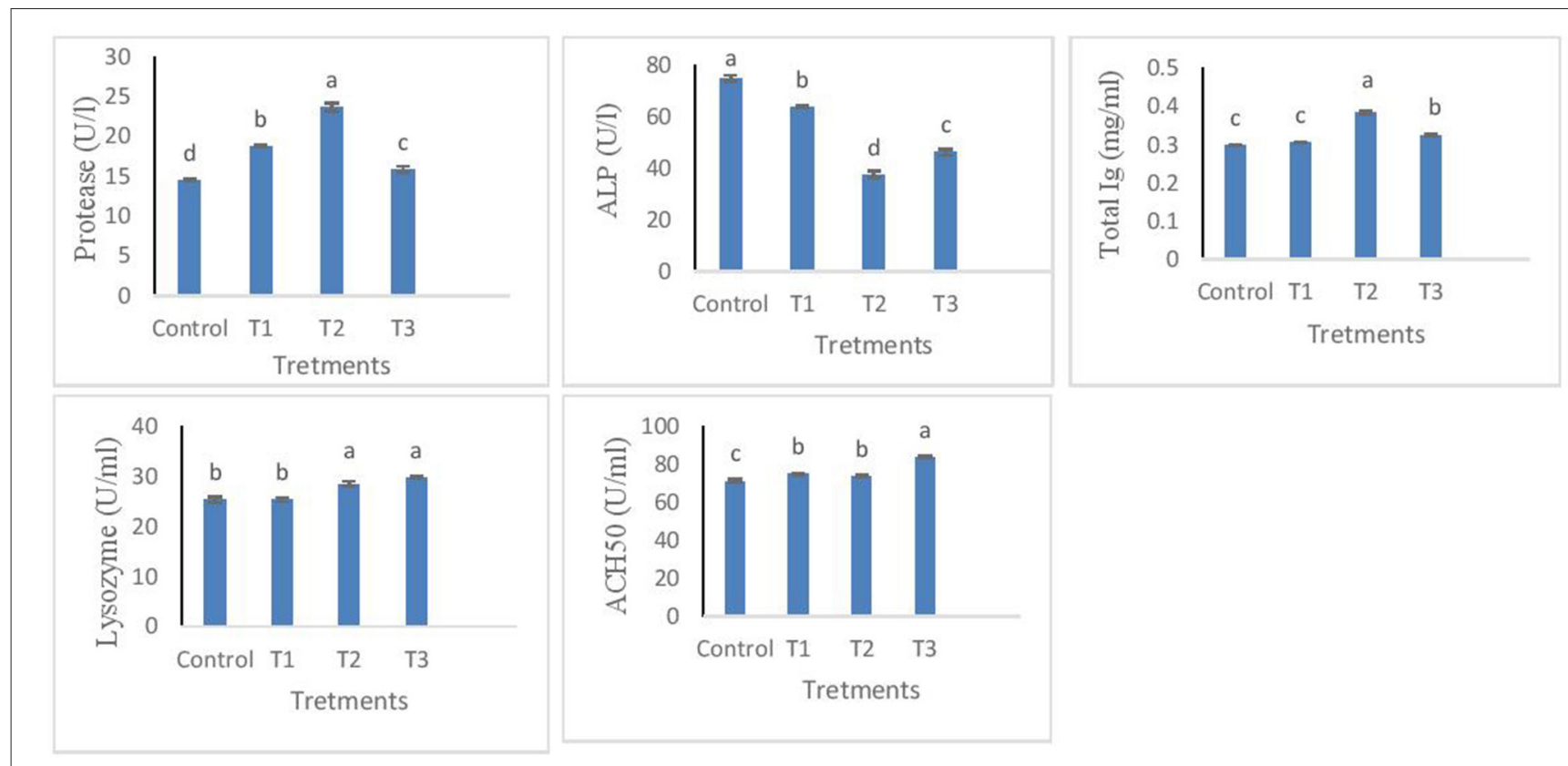

FIGURE 1 | Protease, ALP, total lg, lysozyme, $\mathrm{ACH}_{50}$ levels in the skin mucus of rainbow trout fed diets incorporated with different levels of zero (Control), $0.5 \%$ (T1), $1 \%$ (T2) and $2 \%$ (T3) of a mixture of herbs (Mentha longifolia, Thymus carmanicus, Trachyspermum copticum) for 45 days. Data represent mean \pm SE. Bars with different letters indicate significant differences $(P<0.05)$.

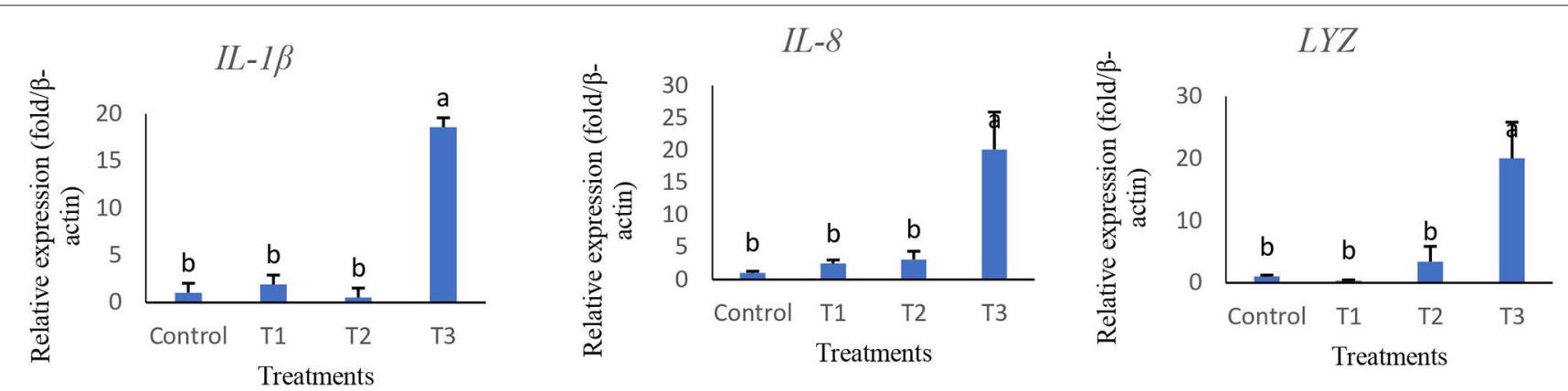

FIGURE 2 | Relative expression of key immune genes of interleukin 1- $\beta$ (IL-1 $\beta$ ), interleukin 8 (IL-8), and lysozyme (Lys) in intestine tissue of rainbow trout fed diets incorporated with different levels of zero (Control), 0.5\% (T1), 1\% (T2) and 2\% (T3) of a mixture of herbs (Mentha longifolia, Thymus carmanicus, Trachyspermum copticum) for 45 days. Data represent mean \pm SE. Bars with different letters indicate significant differences $(P<0.05)$.

illustrated that combining five different plant extracts improved weight gain in grouper, Ephinephelus tauvina, by $41 \%$ higher than the control group (42). This finding is similar to the results reported by Ji et al. (43) when fed olive flounder (Paralichthys olivaceus) with four different plant extracts.

In the present study, the activity of digestive enzymes was increased in T1 and T2, with a slight decrease in T3. Similar effects have been found for different plant extracts tested on various fish species $(44,45)$. In a recent study by Ghafarifarsani et al. (28), a combination of medicinal plants was found effective on digestive enzymes regardless of the inclusion level. However, in the present study, the activity of digestive enzymes was decreased in the highest inclusion levels.
The biochemical parameters are reliable indicators of fish general health status. The present results showed that the lower level of incorporation of a mixture of plants exerted the best effects. Stress biomarkers were significantly decreased in T2, which suggests that $1 \%$ dietary inclusion was best. This can be further investigated by the combined use of the plants tested in this study as a sedative and/or tranquilizer in aquaculture (46).

Skin mucus functions as the outer layer of the fish defense system which includes several immunological mechanisms such as lysozyme and complement system proteins. Serum immunological parameters are also vital in fish systemic defense capacity. In the present study, all experimental diets containing TMT enhanced both serum and mucosal immune responses in which 0.5 and $1 \%$ inclusion levels elicited better immunological 


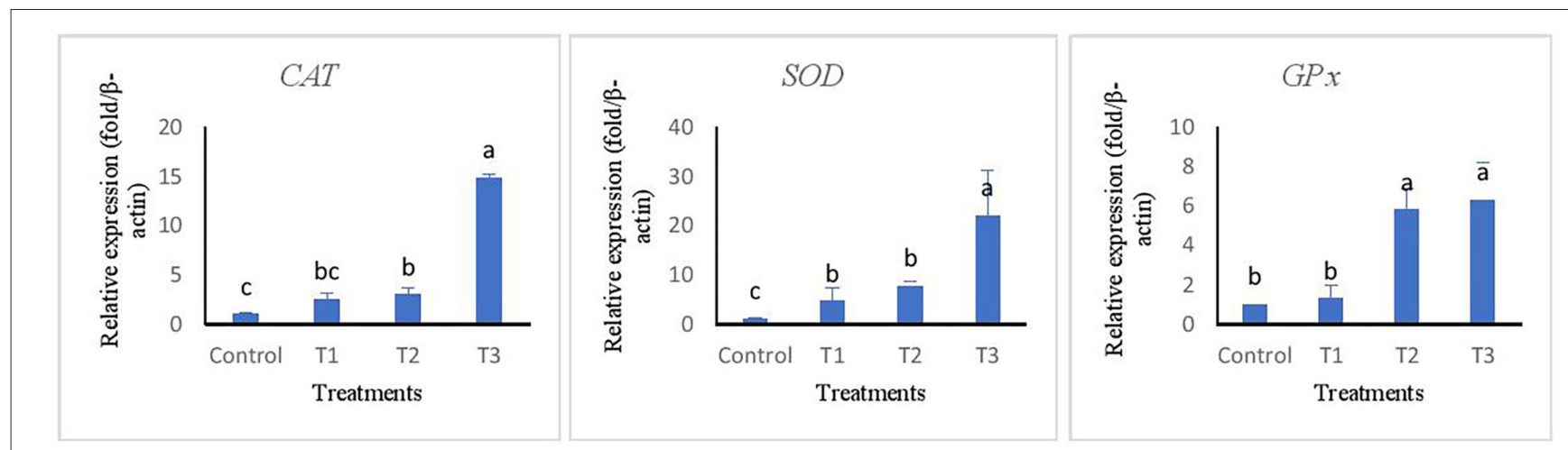

FIGURE 3 | Relative expression of antioxidant related genes of superoxide dismutase (SOD), catalase (CAT), and glutathione reductase (GPx) in liver tissue of rainbow trout fed diets incorporated with different levels of zero (Control), $0.5 \%$ (T1), $1 \%$ (T2) and 2\% (T3) of a mixture of herbs (Mentha longifolia, Thymus carmanicus,

Trachyspermum copticum) for 45 days. Data represent mean \pm SE. Bars with different letters indicate significant differences.

responses both in serum and skin mucus. Similar results are available for the positive effects of plant extracts on the immunological responses of fish $(8,9)$. In a merely similar study, Abdellatief et al. (47) have reported positive effects of combined use of sage (Salvia officinalis) and Spirulina platensis (Arthrospira platensis) on immune responses of Nile tilapia (Oreochromis niloticus). The present findings suggested that $1 \%$ inclusion level was the most significant on different parameters; however, others have suggested better results associated with higher levels. This might be attributed to the excess of bioactive substances disturbing fish immune and antioxidant systems.

Phytochemicals from medicinal plants have been found to modulate the expression of several genes in fish, which has been reviewed recently by Ahmadifar et al. (48). $I L-1 \beta$ is a pro-inflammatory gene released from white blood cells (WBCs), attracting other WBCs and initiating an inflammatory response. In the present study, the transcription of $I L-1 \beta$ was significantly increased in the T3 group, likely suggesting that higher levels of incorporation of TMT induced tissue toxicity in fish. However, fish from the T3 group showed a significantly better growth performance when compared to control and other treatments.

IL- 8 is another cytokine secreted by a variety of tissues and blood cells involved in attracting neutrophils to the inflammation site and acting as an anti-inflammatory factor. Based on present results, IL- 8 was up-regulated in fish receiving TMT. Lysozyme is a critical player in the innate immunity of fish that is coded by a protein-coding gene named $L Y Z$. Similar results were found for the $L Y Z$ gene consistent with increased lysozyme activity in fish receiving TMT.

Zargar et al. (49) have reported a reduction in expression of $I L$ and $L Y Z$ at $2 \mathrm{~mL} / \mathrm{kg}$ concentration of Thymus vulgaris essential oils in the rainbow trout diet. In contrast with present results, a reduction in expression of $I L-1 \beta$ and other pro-inflammatory genes was observed when menthol oil was added to the diet of Nile tilapia (50).

Antioxidative-associated genes in liver tissue were also significantly modulated by TMT where the expression of SOD and CAT was drastically increased in T3, while fish from T1 and
T2 showed relatively lower levels. This finding might suggest that fish were under oxidative pressure caused by TMT, in which case MDA levels were also increased in T3. Similar to the present results, $3 \%$ fenugreek seed powder resulted in an up-regulation of $I L-1 \beta$ and TNF- $\alpha$, reduced levels of AST, and ALT in Nile tilapia (51).

In conclusion, present results suggest that a combination of medicinal plants can be used to enhance the growth and immunity of rainbow trout. Based on gene expression results, it is suggested that a higher inclusion level of a mixture of the plants used in this experiment can trigger inflammatory responses, which is suggested for further research coupled with histological studies. The obtained results in this experiment could be attributed to several present bioactive substances urging further research to identify the main effective substances and their mechanisms of action to modulate immune responses and regulate transcription of critical immune and antioxidant genes.

\section{DATA AVAILABILITY STATEMENT}

The original contributions presented in the study are included in the article/supplementary material, further inquiries can be directed to the corresponding author/s.

\section{ETHICS STATEMENT}

The animal study was reviewed and approved by Islamic Azad University of Shahrekord.

\section{AUTHOR CONTRIBUTIONS}

MR: investigation, data curation, resources, conceptualization, methodology, supervision, and writing and editing. MA, KS, and MM: resources, literature searching, and methodology. GR: writing the original draft and editing. All authors contributed to the article and approved the submitted version. 


\section{REFERENCES}

1. Van Hai $N$. The use of medicinal plants as immunostimulants in aquaculture: a review. Aquaculture. (2015) 446:8896. doi: 10.1016/j.aquaculture.2015.03.014

2. Harikrishnan R, Balasundaram C, Heo MS. Impact of plant products on innate and adaptive immune system of cultured finfish and shellfish. Aquaculture. (2011) 317:1-15. doi: 10.1016/j.aquaculture.2011.03.039

3. Reverter M, Tapissier-Bontemps N, Sarter S, Sasal P, Caruso D. Moving towards more sustainable aquaculture practices: a meta-analysis on the potential of plant-enriched diets to improve fish growth, immunity and disease resistance. Rev Aquac. (2020) 17:1-19. doi: 10.1111/raq.12485

4. Yilmaz E, Taşbozan O, Erbaş C. Potential of medical herbal products to be used in aquaculture. Int J Sci Eng Res. (2018) 9:70-5.

5. FAO. The State of World Fisheries and Aquaculture 2020. Sustainability in action. Rome: FAO (2020). doi: 10.4060/ca9229en

6. Amiri BA, Takami AG. Effects of commercial herbal oil mixture on some hematological, biochemical and immunological parameters of rainbow trout (Oncorhynchus mykiss) and its preventive efficacy against Yersinia ruckeri infection. Iran J Fish Sci. (2020) 19:1304-18. doi: 10.22092/ijfs.2019.119319

7. Mansouri Taee H, Hajimoradloo A, Hoseinifar SH, Ahmadvand $\mathrm{H}$. Dietary Myrtle (Myrtus communis L.) improved non-specific immune parameters and bactericidal activity of skin mucus in rainbow trout (Oncorhynchus mykiss) fingerlings. Fish Shellfish Immunol. (2017) 64:3204. doi: 10.1016/j.fsi.2017.03.034

8. Mohammadi G, Rashidian G, Hoseinifar SH, Naserabad SS, Van Doan H. Ginger (Zingiber officinale) extract affects growth performance, body composition, haematology, serum and mucosal immune parameters in common carp (Cyprinus carpio). Fish Shellfish Immunol. (2020) 99:26773. doi: 10.1016/j.fsi.2020.01.032

9. Salomón R, Firmino JP, Reyes-López FE, Andree KB, González-Silvera D, Esteban MA. The growth promoting and immunomodulatory effects of a medicinal plant leaf extract obtained from Salvia officinalis and Lippia citriodora in gilthead seabream (Sparus aurata). Aquaculture. (2020) 524:735291. doi: 10.1016/j.aquaculture.2020.735291

10. Asbaghian S, Shafaghat A, Zarea K, Kasimov F, Salimi F. Comparison of volatile constituents, and antioxidant and antibacterial activities of the essential oils of Thymus caucasicus, T. kotschyanus and T. vulgaris. Nat Prod Commun. (2011) 6:1934578X.1100600133. doi: 10.1177/1934578X1100600133

11. Gulluce M, Sahin F, Sokmen M, Ozer H, Daferera D, Sokmen A, et al. Antimicrobial and antioxidant properties of the essential oils and methanol extract from Mentha longifolia L. ssp longifolia Food Chem. (2007) 103:144956. doi: 10.1016/j.foodchem.2006.10.061

12. Heydari M, Firouzbakhsh F, Paknejad H. Effects of Mentha longifolia extract on some blood and immune parameters, and disease resistance against yersiniosis in rainbow trout. Aquaculture. (2020) 515:734586. doi: 10.1016/j.aquaculture.2019.734586

13. Patonay K, Szalontai H, Csugány J, Szabó-Hudák O, Kónya EP, Németh ÉZ. Comparison of extraction methods for the assessment of total polyphenol content and in vitro antioxidant capacity of horsemint (Mentha longifolia (L.) L.). J. Appl. Res. Med Aromat. Plants. (2019) 15:100220. doi: 10.1016/j.jarmap.2019.100220

14. Tohidi B, Rahimmalek M, Arzani A. Essential oil composition, total phenolic, flavonoid contents, and antioxidant activity of Thymus species collected from different regions of Iran. Food Chem. (2017) 220:15361. doi: 10.1016/j.foodchem.2016.09.203

15. Boroujeni LS, Hojjatoleslamy M. Using Thymus carmanicus and Myrtus communis essential oils to enhance the physicochemical properties of potato chips. Food Sci Nutr. (2018) 6:1006-14. doi: 10.1002/fsn3.597

16. Jalilzadeh-Amin G, Maham M, Dalir-Naghadeh B, Kheiri F. Effects of Mentha longifolia essential oil on ruminal and abomasal longitudinal smooth muscle in sheep. J Essent Oil Res. (2012) 24:61-9. doi: 10.1080/10412905.2012.646019

17. Mkaddem M, Bouajila J, Ennajar M, Lebrihi A, Mathieu F, Romdhane M. Chemical composition and antimicrobial and antioxidant activities of Mentha (longifolia L. and viridis) essential oils. J Food Sci. (2009) 74:M35863. doi: 10.1111/j.1750-3841.2009.01272.x
18. Gholamhosseini A, Adel M, Dawood MAO, Banaee M. The potential benefits of Mentha longifolia on growth performance and innate immunity parameters in Caspian kutum (Rutilus frisii kutum). Aquac Res. (2020) 51:5212-27. doi: 10.1111/are.14860

19. Zargari A. Medicinal Plants. Tehran: Tehran University of Medical Sciences Publication (1997).

20. Hussein G, Miyashiro H, Nakamura N, Hattori M, Kakiuchi N, Shimotohno K. Inhibitory effects of Sudanese medicinal plant extracts on hepatitis C virus (HCV) protease. Phyther. Toxicol Eval Nat Prod Deriv. (2000) 14:5106. doi: 10.1002/1099-1573(200011)14:7<510::aid-ptr646>3.0.co;2-b

21. Thangam C, Dhananjayan R. Antiinflammatory potential of the seeds of Carum Copticum Linn. Indian J Pharmacol. (2003) 35:388.

22. Huang W, Wang J-Q, Song H-Y, Zhang Q, Liu G-F. Chemical analysis and in vitro antimicrobial effects and mechanism of action of Trachyspermum copticum essential oil against Escherichia coli. Asian Pac J Trop Med. (2017) 10:663-9. doi: 10.1016/j.apjtm.2017.07.006

23. Mahboubi M, Kazempour N. Chemical composition and antimicrobial activity of Satureja hortensis and Trachyspermum copticum essential oil. Iran J Microbiol. (2011) 3:194.

24. Rasooli I, Fakoor MH, Yadegarinia D, Gachkar L, Allameh A, Rezaei MB. Antimycotoxigenic characteristics of Rosmarinus officinalis and Trachyspermum copticum L. essential oils Int J Food Microbiol. (2008) 122:1359. doi: 10.1016/j.ijfoodmicro.2007.11.048

25. Rashidian G, Abedian Kenari A, Nikkhah M. Production and optimization of chitosan nanosystems loaded with peptide fraction resulting from enzymatic hydrolysis of vannamei shrimp (Litopenaeus vannamei) head wastes. Fish Sci Technol. (2021) 10:189-202.

26. Hidalgo MC, Urea E, Sanz A. Comparative study of digestive enzymes in fish with different nutritional habits. Proteolytic and amylase activities. Aquaculture. (1999) 170:267-83. doi: 10.1016/S0044-8486(98)00413-X

27. Bernfeld P. Amylases, alpha and beta. Meth Enzymol. (1955) I:14958. doi: 10.1016/0076-6879(55)01021-5

28. Ghafarifarsani H, Hoseinifar SH, Adorian TJ, Ferrigolo FRG, Raissy M, Van Doan H. The effects of combined inclusion of Malvae sylvestris, Origanum vulgare, and Allium hirtifolium boiss for common carp (Cyprinus carpio) diet: growth performance, antioxidant defense, and immunological parameters. Fish Shellfish Immunol. (2021) 119:670-7. doi: 10.1016/j.fsi.2021.10.014

29. Ortuño J, Esteban MA, Meseguer J. Effects of short-term crowding stress on the gilthead seabream (Sparus aurata L.) innate immune response. Fish Shellfish Immunol. (2001) 11:187-97. doi: 10.1006/fsim.2000.0304

30. Siwicki AK, Anderson DP, Rumsey GL. Dietary intake of immunostimulants by rainbow trout affects non-specific immunity and protection against furunculosis. Vet Immunol Immunopathol. (1994) 41:125-39. doi: 10.1016/0165-2427(94)90062-0

31. Ross NW, Firth KJ, Wang A, Burka JF, Johnson SC. Changes in hydrolytic enzyme activities of naive Atlantic salmon Salmo salar skin mucus due to infection with the salmon louse Lepeophtheirus salmonis and cortisol implantation. Dis Aquat Organ. (2000) 41:43-51. doi: 10.3354/dao041043

32. Livak KJ, Schmittgen TD. Analysis of relative gene expression data using realtime quantitative PCR and the 2- $\Delta \Delta C T$ method. Methods. (2001) 25:4028. doi: $10.1006 /$ meth.2001.1262

33. Pourmoghim H, Haghighi M, Rohani MS. Effect of Dietary inclusion of Origanum vulgare extract on nonspecific immune response and hematological parameters of Rainbow trout (Oncorhynchus mykiss). Bull Environ Pharmacol Life Sci. (2015) 4:33-9. doi: 10.1016/j.aqrep.2020.100511

34. Alagawany M, Farag MR, Salah AS, Mahmoud MA. The role of oregano herb and its derivatives as immunomodulators in fish. Rev Aquac. (2020) 12:2481-92. doi: 10.1111/raq.12453

35. Zheng ZL, Tan JYW, Liu HY, Zhou XH, Xiang X, Wang KY. Evaluation of oregano essential oil (Origanum heracleoticum L.) on growth antioxidant effect and resistance against Aeromonas hydrophila in channel catfish (Ictalurus punctatus). Aquaculture. (2009) 292:214-8. doi: 10.1016/j.aquaculture.2009.04.025

36. Ahmadifar E, Falahatkar B, Akrami R. Effects of dietary thymol-carvacrol on growth performance, hematological parameters and tissue composition of juvenile rainbow trout, Oncorhynchus mykiss. J Appl Ichthyol. (2011) 27:1057-60. doi: 10.1111/j.1439-0426.2011.01763.x 
37. Giannenas I, Triantafillou E, Stavrakakis S, Margaroni M, Mavridis S, Steiner T. Assessment of dietary supplementation with carvacrol or thymol containing feed additives on performance, intestinal microbiota and antioxidant status of rainbow trout (Oncorhynchus mykiss). Aquaculture. (2012) 350:26-32. doi: 10.1016/j.aquaculture.2012.04.027

38. Harikrishnan R, Balasundaram C, Heo MS. Effect of Inonotus obliquus enriched diet on hematology, immune response, and disease protection in kelp grouper, Epinephelus bruneus against Vibrio harveyi. Aquaculture. (2012) 344:48-53. doi: 10.1016/j.aquaculture.2012.03.010

39. Pavaraj M, Balasubramanian V, Baskaran S, Ramasamy P. Development of immunity by extract of medicinal plant Ocimum sanctum on common carp Cyprinus carpio (L.). Res J Immunol. (2011) 4:12-8. doi: 10.3923/rji.2011.12.18

40. Takaoka O, Ji S-C, Ishimaru K, Lee S-W, Jeong G-S, Ito J. Effect of rotifer enrichment with herbal extracts on growth and resistance of red sea bream, Pagrus major (Temminck \and Schlegel) larvae against Vibrio anguillarum. Aquac Res. (2011) 42:1824-9. doi: 10.1111/j.1365-2109.2010.02783.x

41. Shalaby AM, Khattab YA, Abdel Rahman AM. Effects of garlic (Alliumsativum) and chloramphenicol on growth performance, physiological parameters and survival of Nile tilapia (Oreochromis niloticus). J Venom Anim Toxins Incl Trop Dis. (2006) 12:172201. doi: 10.1590/S1678-91992006000200003

42. Punitha SMJ, Babu MM, Sivaram V, Shankar VS, Dhas SA, Mahesh TC. Immunostimulating influence of herbal biomedicines on nonspecific immunity in Grouper Epinephelus tauvina juvenile against Vibrio harveyi infection. Aquac Int. (2008) 16:511-23. doi: 10.1007/s10499-007-9162-6

43. Ji S-C, Jeong G-S, Gwang-Soon IM, Lee S-W, Yoo J-H, Takii K. Dietary medicinal herbs improve growth performance, fatty acid utilization, and stress recovery of Japanese flounder. Fish Sci. (2007) 73:70-6. doi: 10.1111/j.1444-2906.2007.01303.x

44. Rashidian G, Bahrami Gorji S, Farsani MN, Prokić MD, Faggio C. The oak (Quercus brantii) acorn as a growth promotor for rainbow trout (Oncorhynchus mykiss): growth performance, body composition, liver enzymes activity and blood biochemical parameters. Nat Prod Res. (2018) 34:2413-23. doi: 10.1080/14786419.2018.1538994

45. Rashidian G, Kajbaf K, Prokić MD, Faggio C. Extract of common mallow (Malvae sylvestris) enhances growth, immunity, and resistance of rainbow trout (Oncorhynchus mykiss) fingerlings against Yersinia ruckeri infection. Fish Shellfish Immunol. (2020) 96:254-61. doi: 10.1016/j.fsi.2019.12.018

46. Yousefi M, Hoseini SM, Vatnikov YA, Nikishov AA, Kulikov EV. Thymol as a new anesthetic in common carp (Cyprinus carpio): efficacy and physiological effects in comparison with eugenol. Aquaculture. (2018) 495:376-83. doi: 10.1016/j.aquaculture.2018.06.022
47. Abdellatief SA, Abdel Rahman AN, Abdallah FDM. Evaluation of Immunostimulant activity of Spirulina platensis (Arthrospira platensis) and Sage (Salvia officinalis) in Nile tilapia (Oreochromis niloticus). Zagazig Vet J. (2018) 46:25-36. doi: 10.21608/zvjz.2018.7621

48. Ahmadifar E, Pourmohammadi Fallah H, Yousefi M, Dawood MAO, Hoseinifar $\mathrm{SH}$, Adineh $\mathrm{H}$. The gene regulatory roles of herbal extracts on the growth, immune system, and reproduction of fish. Animals. (2021) 11:2167. doi: 10.3390/ani11082167

49. Zargar A, Rahimi-Afzal Z, Soltani E, Taheri Mirghaed A, EbrahimzadehMousavi HA, Soltani M. Growth performance, immune response and disease resistance of rainbow trout (Oncorhynchus mykiss) fed Thymus vulgaris essential oils. Aquac Res. (2019) 50:3097-106. doi: 10.1111/ar e. 14243

50. Dawood MAO, Metwally AE-S, Elkomy AH, Gewaily MS, Abdo SE, Abdel-Razek MAS. The impact of menthol essential oil against inflammation, immunosuppression, and histopathological alterations induced by chlorpyrifos in Nile tilapia. Fish Shellfish Immunol. (2020) 102:316-25. doi: 10.1016/j.fsi.2020.04.059

51. Moustafa EM, Dawood MAO, Assar DH, Omar AA, Elbialy ZI, Farrag FA. Modulatory effects of fenugreek seeds powder on the histopathology, oxidative status, and immune related gene expression in Nile tilapia (Oreochromis niloticus) infected with Aeromonas hydrophila. Aquaculture. (2020) 515:734589. doi: 10.1016/j.aquaculture.2019.734589

Conflict of Interest: The authors declare that the research was conducted in the absence of any commercial or financial relationships that could be construed as a potential conflict of interest.

Publisher's Note: All claims expressed in this article are solely those of the authors and do not necessarily represent those of their affiliated organizations, or those of the publisher, the editors and the reviewers. Any product that may be evaluated in this article, or claim that may be made by its manufacturer, is not guaranteed or endorsed by the publisher.

Copyright (C) 2022 Raissy, Ahmadi Kabootarkhani, Sanisales, Mohammadi and Rashidian. This is an open-access article distributed under the terms of the Creative Commons Attribution License (CC BY). The use, distribution or reproduction in other forums is permitted, provided the original author(s) and the copyright owner(s) are credited and that the original publication in this journal is cited, in accordance with accepted academic practice. No use, distribution or reproduction is permitted which does not comply with these terms. 